\title{
Competence of Lecturers and Students in Using Formulaic Sequence in Blended Speaking Classroom using Edmodo
}

\author{
Radeni Sukma Indra Dewi ${ }^{1}$, Januarius Mujiyanto ${ }^{2}$, Dwi Rukmini ${ }^{3}$, Mursid Saleh ${ }^{4}$ \\ \{radenisukmaindradewi@gmail.com ${ }^{1}$ \} \\ 1,2,3,4 UNNES, Pasca Sarjana Unnes Jalan Kelud Utara III Semarang 50237, Indonesia
}

\begin{abstract}
The distinction between lecturers and students in their use of the identified formulaic sequences may not be a matter of competence as some researchers assumed. The finding revealed that formulaic sequences promote efficiency in tasks in general as the time needed to finish the tasks decreases when more identified sequences were used. The discourse function of formulaic sequences, however, differed in the sense that they helped subjects construct longer discourse in the picture task but shorter discourse in the problem-solving task. Lecturers in this study used more identified formulaic sequences than students but this difference was only significant in the picture task but not in the problem-solving task. However, among the lecturers and students, three styles of formulaic sequences use could be identified. The first pattern was that subjects used more formulaic sequences in the picture task than in the problem-solving task. The second pattern was vice versa; and the third pattern was subjects have similar use of identified formulaic sequences in both tasks. As these three groups balanced each other, t-test between all subjects' use of formulaic sequences in the two tasks was not statistically significant.
\end{abstract}

Keywords: Formulaic Sequences, Lecturers Competence, Students Competence, Blended Speaking Classroom using Edmodo

\section{Introduction}

One of the important components in Communicative Competence's Theory by Celce Murcia, 2007 [1] is formulaic competence which enables students to create natural and fluent spoken and written texts. Formulaic competence refers to recurrent fixed chunks/expressions used by native speakers to communicate with the others consists of conversational formulas, pause fillers, collocations, idioms, conversation phrases, lexical bundles, proverbs, expletives and routines. In creating a text, students learn grammar, vocabulary, and pronunciation but they also have to be aware of social factors by which the language is influenced so that the text will be socially accepted.

Students rarely used and applied formulaic expressions in classroom interaction, deal with the poor formulaic speech of students, the teacher can foster the students to be exposed more to activities, lessons, and practices to improve their formulaic competence. Formulaic speech needs to be introduced to students as a preparation before they hand the real communication. In some universities, the demand for learning English rises from time to time because English used as a medium of instruction in blended learning classroom. Even though the status of English is a foreign language in Indonesia was so lack genuine situation to speak the language.

English native speakers tend to use conversational formulas, pause fillers, collocations, idioms, conversation phrases, lexical bundles, proverbs, expletives and routines. Deal with the language experience, university students should be exposed to formulaic expressions to be in native-like fashion. Unfortunately, 
many University students have tendency to ignore in producing formulaic expressions like native because they still have to solve their anxiety in speaking English. Kecskes [2] argues the reason why non-native speakers find difficulties to produce natural expressions because non-native speakers have different language experiences from native speakers. The language experiences from everyday conversation and speaking in English culture tends to forced the speaker to use a lots of formulaic expressions.

In other words, formulaic speech can help students develop their formulaic competence and strategic competence. The memorized expressions can also help students develop their linguistic competence because they can refer to the structure of the fixed expressions they use. In fact, they can also learn about the target culture through the expressions, when and how the expressions are said appropriately within certain discourse. Up to this point, the writer argues that formulaic competence is crucial for a second language speaker and writer. The formulaic speech can help students survive in unpredictable language use.

In literature, linguists in general have a consensus that formulaic sequences play an important role in fluency in speech. Wood, 2001 [3] suggested that speaking is an every day but difficult task as it requires a balance of attention, word choice, hearer manipulation and ideas. Therefore, the efficiency of online planning determines the fluency of the speaker. With the extensive use of formulaic language, memory load for online planning can be alleviated. Among other features which characterize the lecturers' or advanced learners' speech, fluency is one of the most well-discussed aspects from Wood, 2001 [4].

A study on competence and competence of communicative competence in learning and teaching English were carried out by [5]-[7] Epstein, Flynn, \& Martohardjono, 1996; Newby, 2011; Tuan, 2017 pointed that low discourse competence among learners is influenced by their low English language exposure and less focus of English Language Teaching dimension. Structurally, the low discourse competence is accounted to the fact that English language is treated as a foreign language and not as a second language. Such policy in the country impedes the development of language proficiency of the learners in the English language. Specifically, the field of specialization spells out differences in communicative competence of the learners in as much as the expected level of communicative competencies in different professions vary. Finally, grammatical and discourse competence among learners is influenced by their English language exposure. The more exposed the learners in the English language, the higher is their communicative competence.

Sinclair [8] conduct a research creates a useful list of formulaic sequences for academic speech and writing, called the Academic Formulas List (AFL). The AFL here consist of (i) frequent recurrent patterns in corpora of written and spoken the language, which (ii) occur significantly more often in academic than in non-academic discourse, and (iii) inhabit a wide range of academic genres. AFL separately lists formulas that are common in academic spoken and academic written language. AFL also prioritizes formulas using an empirically derived measure of utility that is educationally and psychologically valid and operationalizable with corpus linguistic metrics. Later, the formulas were classified according to their predominant pragmatic function for descriptive analysis and in order to marshal the AFL for inclusion in English for Academic Purposes instruction.

A study on formulaic expressions used in conversation text was carried out by Mustapa, Yaholil \& Agustien, 2017; Sugiati \& Rukmini, 2017 [9], [10] showed that there are four forms of formulaic expressions identified in the conversational texts. There were only four out of five formulaic expressions types as formulated by Biber et al. (1999) [11]. They were lexical bundles, idiomatic phrases, collocations, and inserts. Based on these findings, there are many conversational texts that do not sound natural; consequently, there must be some revisions.

Another study on formulaic expressions used in students interaction and casual conversation were conducted by [12], [13] Khusnita, Dafi \& Rukmini, 2016; Neno \& Agustien, 2016 showed that EFL students need formulaic expressions to be sound natural and fluent in speaking. The research revealed that most of the students used collocations, lexical bundles, inserts, idioms, and binomial expressions. Students mostly used collocations and lexical bundles since they were more familiar with the literal meanings. Eventhough, most students produced unnatural expressions in classroom interactions, since they need more time to process formulaic expressions, since they combine English with their first language. Furthermore, it is found that learners" problem in realizing formulaic sequences includes the tendency to simply use the expressions they heard from any sources without considering the appropriateness of the expressions, the difficulty in using correct formulaic sequences to be used in the given situation, the idiomaticity of formulaic sequences, the tendency to translate Indonesian expressions into English literally word by word, and problems related to grammar. 
A research on classroom interaction pattern was conducted by Rafieerad, 2010 [14] revealed that it is necessary for the lecturers to reorganize the activities which can facilitate the students to act more in the classroom interaction, such as brainstorming, problem-solving, cooperative learning, role play, simulations, discussion, and etc. Using such activities in the classroom, lecturers will be able to motivate students to learn in a more involving way. Classroom interaction activities can stimulate the students to have positive attitude towards language learning. Moreover, students must be persuaded to interact positively and effectively in the language classroom. Lecturers should incorporate more real life like activities into their teaching practice such as 'problem-solving', 'information-gap tasks' and the like.

The information of the study background reveal the reasons why this study is essential to do. They are, first, most EFL student lecturers in Indonesia stated that they experienced difficulties due to unfamiliar vocabulary and a limited number of examples in formulaic expressions. Second, based on preliminary research at Universitas Muhammadiyah Semarang in May $7^{\text {th }}, 2018$, it is revealed that Second Language (L2) Learners of English tend to produce incorrect or deviant collocations in their second language spoken outputs, because of their failure to recognize it as a formulaic expression to be learned.

The above-mentioned studies inspired researchers to conduct a study in the same area, formulaic expressions, but with a different focus. The researchers willing to investigate the real use of formulaic expressions by Indonesian EFL lecturers and students in blended learning classroom interaction using Edmodo. Lecturers here analogized with the term of "Native Speaker", in case of the competence of Lecturers in English Education Study Program which almost have the same competence with Native Speaker. And Students here analogized with the term of "Non Native Speaker", in case of the competence of students which still needs to be improved more in the use of formulaic language. The participants of the study are the lecturers and also students of the first and second semester of English Department of Universitas Muhammadiyah Semarang.

\section{Methods}

After a review of literature, it turns out that the difference between lecturers and students should be worth more investigation. This study set out to extend the investigation on how lecturers and students differ in their use of formulaic sequences in other conditions such as task types. Other aims of this study were to explore empirically the relationship between formulaic language and fluency and discourse functions of formulaic language. In the review of literature, it is found that many researchers have reported their observations or speculations about the function of formulaic language in enhancing fluency and improving discourse organization but there is a lack of empirical evidence. So in this study, aspects of fluency and discourse organization were measured and tested to see if and how they are related to formulaic language.

Finally, this study investigated the phonological features of formulaic sequences and attempted to validate the use of changes in rate of articulation as a way of detecting formulaicity. This research was a corpus study, which defined as a piece of language text collection in electronic form selected according to external criteria, as far as possible to represent a language or language variety as a source of data for linguistic Aini, Faridi, \& Fitriati, 2018 [15]. In answering the research questions, the researcher did some steps, started with the tasks, the subjects, data collection, and data analysis.

\subsection{The Tasks}

In this study, two types of tasks, namely a picture task and a decision-making task, were investigated. In the picture task, there were two sets of pictures; each containing 6 frames. The first set of pictures was about two children going on a picnic and the second set of pictures was about getting back a football from a big hole. The pictures were clearly drawn and the idea was very straightforward such that the plot behind the pictures could be understood easily by both the subjects and their partners. The subjects' task was to work in pairs and tell the story in the pictures to their partner, who did not have the pictures with them. When the first speaker finished his/her story, the listener raised questions about the story and then the first speaker had to answer the questions. When the listener had no more questions, the partner starts telling the story in his/her own set of pictures.

The decision-making task contained three letters to the Agony Aunt, each specifying a problem related to love affairs. The three problems should be interesting to the subjects and they did not find the problems too easy or too difficult. The subjects' task was to work in pairs to negotiate with their partner and agree on one solution to the problem. Before the interactions started, subjects were given 10-minute individual planning time 
to look at the pictures or the three letters and to plan what they wanted to say about them. The subjects were allowed to write notes but they were not allowed to look at the notes when they did the task. For all pairs of subjects, the picture task was done first, followed by the problem-solving task.

\subsection{The Subjects}

The subjects in this study were 10 lecturers and 10 students in blended speaking classroom using Edmodo. The subjects were not asked to do proficiency tests for this study but their English proficiency should be around intermediate to upper intermediate considering the language proficiency requirement for entrance into the university and the fact that the participants of the English language courses were usually those who had difficulty using English in their academic studies. The two groups of 10 participants were randomly assigned to form pairs with other members in their group and do the two tasks.

\subsection{Data Collection}

Each session of data collection was done in a quiet and comfortable room by the researchers with each pair of subjects. When the researchers finished introducing themselves, the subjects were told what they needed to do in the experiment and that their competences would be recorded. When the subjects were ready to start after 10 minutes' pre-task planning time, they talked until they had nothing more to add. The researchers did not interrupt when the subjects were interacting. Adding up the planning time and task time, the two tasks took around 40 minutes to finish. There were also individual interviews immediately after each of the two tasks in which questions about the subjects' planning behavior were asked. However, data from the interviews were not analyzed because the primary focus was put on the subjects' use of formulaic sequences.

\subsection{Data Analysis}

The competences of the subjects in the two tasks were recorded using a digital audio recorder. The two hours of recordings were transcribed to form a 20,000-word corpus. The transcribed texts were then analyzed both quantitatively and qualitatively. The first step was to identify formulaic sequences with the help of a corpus tool called Word Smith 4.0. As mentioned in the previous sections, formulaic sequences were operationalized in this study as a continuous sequence of at least 3 words that occurred in the same form (inflections of plural and tense excluded) at least 4 times in at least 4 out of the 20 transcript in the corpus. In the search, abbreviations like $-' s,-' l l,-' d$ were taken as equal to their original form $i s$, will, would, and thus $h e^{\prime} l l$ are two words.

In order to preserve the objectivity of the study, all recurrent sequences extracted by automatic retrieval were not filtered. The unit of measurement for use of formulaic sequences was number of sequences per minute. For the relationship of formulaic competence with fluency and discourse organization, the data were coded with time features with a sound wave editor software called Goldwave Version 4.26. This editor software helped to process the digitized recordings by visualizing the sound waves on the screen. Combining audio and visual evidence, the researcher was able to measure, correct to milliseconds, the duration of each turn and pause. Following Freed, 1995 [15], a pause in this study was defined as an unfilled (silent) pause of 0.4 seconds or longer. With the information about the duration of turns and pauses, fluency-related indicator variables such as speech rate and pausing rate, number of turns, mean duration of turns were calculated.

\section{Results and Discussion}

\subsection{Use of Formulaic Expressions by Lecturers and Students}

In this study, it was found that lecturers outperformed (with statistical significance in t-test) students in the number of identified formulaic sequences used only in the picture task but not in the problem-solving task. Arranging the mean use of the identifies formulaic sequences in the four situations in order, it was found that lecturers in the picture task recorded the greatest use of formulaic sequences, followed by lecturers in the problem-solving task and then students in the picture task. Students in the picture task recorded the least use of formulaic sequences. In other words, the picture task had the potential to distinguish lecturers from students.

This finding is very interesting in itself because, unlike many studies Paquot, 2012 \& Howard, 2006 [16], [17] which found that lecturers always outperformed students in their use of formulaic sequences, this study suggested that the advantage may not be absolute and task type seem to play an important role.

Compared with the problem-solving task, the picture task was more difficult in the sense that it required 
the subjects to talk for two to three minutes without stopping. So in order to buy time to do online planning while maintaining a high speech rate, speakers needed to use both pausing and formulaic sequences as a strategies. On the other hand, the problem-solving task was dialogic in nature. The interlocutors could have time to plan when the other was speaking and they had plenty of time to respond when they felt ready to do so.

Lecturers, who were better in this study in using pauses and formulaic sequences as strategies to help them maintain a high speech rate, obviously showed their advantage in the more difficult picture task (refer to Table 1).

Table 1. Mean speech rate, standardized number of pauses and use of formulaic sequences by lecturers and students in the picture task

\begin{tabular}{lll}
\hline & Lecturers & Students \\
\hline $\mathrm{n}$ & 10 & 10 \\
\hline Mean speech rate (word per min) & 250.07 & 171.30 \\
\hline Number of pauses & 27.84 & 21.14 \\
\hline Use of formulaic sequences (per minute) & 8.52 & 3.90 \\
\hline
\end{tabular}

To explain why lecturers are better in using formulaic sequences as a strategy to buy time for online planning, some researchers Granger, 2014 \& Pawley, 1992 [18], [19] may suggest that is because lecturers have a bigger store of formulaic sequences since they were graduated from reputable university in English education. While this may be true in most contexts, it may not be the sole explanation; at least the findings in this study seemed to suggest that lecturers and students did not appear to differ in their use of formulaic sequences in the problem-solving task. ( $\mathrm{t}=1.128$, n.s.).

More cognitive studies should be done perhaps before we can sure if lecturers really have a bigger store of formulaic sequences than students. If it is as suggested in the findings of this study that students have their own store of formulaic sequences which may be bigger, smaller or equal in size to that of the lecturers, then the problem becomes why students in this study did not make full use of formulaic sequences in the picture task which is more difficult.

Indeed, in the picture task, the lecturers who recorded the highest use of formulaic sequences (i.e., 13.33 sequences per minute) used 3 times as many sequences than the mean for the students in general (i.e., 3.90 sequences per minute). The simplest reason for this may be that students may not be aware that formulaic sequences can be a strategy in speaking and they prefer to slow down their speech to buy time for online planning.

\subsection{Interaction Between Lecturers/Students Factor and Task Type}

By further dividing the mean use of formulaic language by lecturers and students according to task type, it was found that lecturers in the picture task and students in the picture task recorded respectively the highest and lowest amount of formulaic expressions use (refer to Table 2). In the middle was lecturers in the problem-solving task, followed by the students in the problem-solving task.

Table 2. Mean Use of Formulaic Expressions per minute by lecturers and students in the two tasks

\begin{tabular}{lllll}
\hline & & $\mathrm{n}$ & Mean & SD \\
\hline Picture Task & $\mathrm{NNS}$ & 10 & 3.90 & 1.81 \\
\cline { 2 - 5 } & $\mathrm{NS}$ & 10 & 8.52 & 3.58 \\
\hline Problem-solv & $\mathrm{NNS}$ & 10 & 5.24 & 1.48 \\
\cline { 2 - 5 } ing Task & $\mathrm{NS}$ & 10 & 6.37 & 2.81 \\
\hline
\end{tabular}

Even though the lecturers were found to have used more formulaic sequences in the two tasks than the students, the difference between them in the problem-solving task was very small. While lecturers and students in this study differed significantly in their use of formulaic sequences in the picture task $(\mathrm{t}=3.64, \mathrm{p}<0.01)$, there were no statistical significance in their difference in the problem-solving task. $(\mathrm{t}=1.13$, n.s.).

Correlation between subjects' individual competence in the picture task and the problem-solving task, surprisingly, was not significant $(\mathrm{r}=1.15$, n.s.). This means the subjects ' pattern of use of formulaic expressions in the two tasks was not consistent as people normally expect. Some subjects used more formulaic expressions in the picture task than in the problem-solving task but others just demonstrated an opposite pattern of use. So it 
will be interesting to find out what affects individuals‘ unconscious decisions about when to use more or less formulaic expressions.

The fact that lecturers and students only different in their use of formulaic language in the picture task but not in the problem-solving task revealed that students may not necessarily have a smaller store of formulaic sequences as many linguists assume. If lecturers' store of sequences is bigger than that of the students, one may expect to find significant difference in their competence in the two tasks. So there is a potential that lecturers and students have stores of formulaic sequences that are comparable in size (note that what are stored as formulaic sequences can be different between lecturers and students. The findings in this study only showed that students did not use as many formulaic sequences in the picture task as the lecturers.

\subsection{Fluency and the Use of Formulaic Language}

In this analysis correlations between mean use of formulaic language and speech rate (words per minute), standardized number of pauses and mean duration of each pause (in seconds) where calculated separately for the two tasks. However, none of these correlations was statistically significant. Subsequent calculation of the correlations between fluency and use of formulaic language by separating the lecturers and students groups, however, found that use of formulaic sequences by lecturers was highly correlated with mean duration of each pause, $r=-.64, p<0.05$. In other words, the more formulaic sequences used by lecturers in the picture task, the shorter the pauses.

Table 3. Correlations of Formulaic Sequences Use with Speech Rate, Number of Pauses, and Mean Duration of Each Pause (combining the lecturers and students group)

\begin{tabular}{lll}
\hline & Picture Task & $\begin{array}{l}\text { Problem-sol } \\
\text { ving Task }\end{array}$ \\
\hline $\begin{array}{l}\text { Speech rate } \\
\text { (pauses }\end{array}$ & $\mathrm{r}=.27, \mathrm{n} . \mathrm{s}$. & $\mathrm{r}=.22, \mathrm{n} . \mathrm{s}$. \\
$\begin{array}{l}\text { included in } \\
\text { calculation) }\end{array}$ & & \\
\hline $\begin{array}{l}\text { Speech rate } \\
\text { (pauses }\end{array}$ & $\mathrm{r}=.27, \mathrm{n} . \mathrm{s}$. & $\mathrm{r}=.17, \mathrm{n} . \mathrm{s}$. \\
$\begin{array}{l}\text { excluded in } \\
\text { calculation) }\end{array}$ & & \\
\hline $\begin{array}{l}\text { Standardized } \\
\text { number } \\
\text { pauses }\end{array}$ & $\mathrm{r}=.09, \mathrm{n} . \mathrm{s}$. & $\mathrm{r}=-.23, \mathrm{n} . \mathrm{s}$. \\
\hline $\begin{array}{l}\text { Mean duration } \\
\text { of each pause }\end{array}$ & $\mathrm{r}=-.26, \mathrm{n} . \mathrm{s}$. & $\mathrm{r}=.14, \mathrm{n} . \mathrm{s}$. \\
\hline
\end{tabular}

As Table 4 below shows, the lecturers and students groups differed significantly in fluency measures including standardized number of pauses in the picture task and speech rate including and excluding pauses in calculation in both tasks. Specifically, lecturers paused more but spoke faster than students.

Table 4. Mean Duration of Each Pause, Number of Pauses and Speech Rate for Lecturers and Students Across the Two Tasks

\begin{tabular}{|c|c|c|c|c|c|}
\hline & & \multicolumn{2}{|c|}{ Picture Task } & \multicolumn{2}{|c|}{$\begin{array}{l}\text { Problem-solving } \\
\text { Task }\end{array}$} \\
\hline & & Mean & SD & Mean & SD \\
\hline \multirow{3}{*}{$\begin{array}{l}\text { Duration of Each } \\
\text { Pause }\end{array}$} & $\mathrm{T}$ & .77 & .20 & .88 & .20 \\
\hline & $\mathrm{S}$ & .84 & .23 & .77 & .20 \\
\hline & & \multicolumn{2}{|c|}{$\mathrm{t}=.75$,n.s. } & \multicolumn{2}{|c|}{$\mathrm{t}=1.19$,n.s. } \\
\hline \multirow{3}{*}{$\begin{array}{l}\text { Standardized Number } \\
\text { of Pauses }\end{array}$} & $\mathrm{T}$ & 21.14 & 4.77 & 19.47 & 3.67 \\
\hline & $S$ & 27.84 & 8.77 & 18.63 & 3.70 \\
\hline & & \multicolumn{2}{|c|}{$\mathrm{t}=2.12, \mathrm{p}<.05$} & \multicolumn{2}{|c|}{$\mathrm{t}=.51, \mathrm{n} . \mathrm{s}$. } \\
\hline \multirow{2}{*}{$\begin{array}{l}\text { Speech Rate } \\
\text { Including Pauses }\end{array}$} & $\mathrm{T}$ & 131.19 & 22.93 & 130.37 & 29.61 \\
\hline & $\mathrm{S}$ & 178.83 & 49.09 & 206.50 & 67.10 \\
\hline
\end{tabular}




\begin{tabular}{llllll}
\hline & & \multicolumn{2}{l}{$\mathrm{t}=2.78, \mathrm{p}<.05$} & \multicolumn{2}{l}{$\mathrm{t}=3.28, \mathrm{p}<.01$} \\
\hline Speech Rate & $\mathrm{T}$ & 171.30 & 28.25 & 177.68 & 48.28 \\
\cline { 2 - 6 } Excluding Pauses & $\mathrm{S}$ & 250.07 & 72.10 & 267.11 & 98.91 \\
\cline { 2 - 6 } & & $\mathrm{t}=2.18, \mathrm{p}<.01$ & $\mathrm{t}=2.57, \mathrm{p}<.05$ \\
\hline
\end{tabular}

Bearing in mind the previous findings that 1) lecturers and students in the picture task represented respectively the highest and lowest use of formulaic language and 2) they only differed significantly, as shown in the t-test result, in the picture task but not in the problem-solving task, the findings about the standardized number of pauses shown in Table 5 above appear interesting. The lecturers demonstrated the greatest number of standardized pauses and this number differed significantly from that of the students $(\mathrm{t}=2.12, \mathrm{p}<05)$ only in the picture but not the problem-solving task. This pattern of pauses looked similar to the pattern of formulaic language use. From the means calculated, perhaps it can be suggested that the number of pauses may be related to the use of formulaic language in the sense that lecturers choose to pause and/or use formulaic sequences when they need to plan online so that when lecturers do speak, they can maintain a high speech rate.

The fact that all values of $t$ related to the speech rates in Table 4 are greater than 2.5 suggests that lecturers had significantly higher speech rates than students across the two tasks. For students, their speech rate was incomparable to that of the lecturers and they used less formulaic sequences and paused less. This means they did not quite use pausing nor formulaic sequences to help with their speech rate.

Contrary to prediction of researchers Wood, 2001 \& Wray, 1999 [4], [20] in this study, formulaic language use did correlate with any of the three fluency measures (mean duration of each pause, standardized number of pauses and speech rate) in the two tasks. However, instead of concluding that formulaic language does not enhance fluency, more studies should be done to investigate if formulaic language has enhanced fluency in ways that are measured in terms of length of fluent runs or location of pauses as Wood, 2001 [4] suggested. Another possibility may be to find two other groups of students who represent the beginner and the advanced learners and find out if and how their use of formulaic language and speech rate correlate.

When the lecturers and students were considered separately, however, it showed that for the lecturers, mean duration of each pause correlated with formulaic sequences use $(r=-.64, p<0.05)$ in the way that the greater the use of formulaic sequence, the shorter the pauses. This finding fit in with has been proposed that lecturers were better at using pausing and formulaic sequences as strategies to buy time for online planning so that a high speech rate could be achieved.

Taking into account the interplay between lecturers/students factor and the task type factor, it was found that for the number of standardized pauses, lecturers only differed significantly with the students in the picture task but not in the problem-solving task. So even though there was no correlation between the use of formulaic language and the three fluency measures, future studies can be done to investigate the nature of the relationship between number of pauses and use of formulaic language.

\subsection{Time on Task and the Use of Formulaic Language}

The part of findings about time on task and length of each turn is related to the discourse functions played by formulaic sequences. In interactions, formulaic sequences function to promote efficiency of information exchange and enhance accuracy in encoding and decoding information. According to Wray, 1999 [21] these sequences also enable speakers to hold their turn and be heard out, so the interactions appear to be smoother.

It is clear that students' time on task in this study was twice as much as the lecturers's in the picture task $(\mathrm{t}=3.75, \mathrm{p}<0.01)$ and the problem-solving task $(\mathrm{t}=3.96, \mathrm{p}<0.01)$. So it appears that lecturers who had significantly greater use of formulaic sequences in the picture task also finished their tasks earlier than their students counterparts. In a sense, this may suggest that the use of formulaic language affects time on task. However, it is important to also consider the number of words and the number of speech units (measured by AS unit, foster tonkyn wigglesworth 2000) made by the two groups. As shown in Table 5, both the number of words and the number of AS-units are larger for the students than the lecturers, meaning students took longer time to finish the task perhaps because they have more to say.

Table 5. Mean Number of Words and AS Units for Lecturers and Students Across the Two Tasks

\begin{tabular}{|c|c|c|c|}
\hline & & Students & Lecturers \\
\hline Picture Task & Word & $355.40(\mathrm{SD}=123.81)$ & $285.60(\mathrm{SD}=104.40)$ \\
\hline
\end{tabular}




\begin{tabular}{llll}
\hline & AS-unit & $36.80(\mathrm{SD}=15.48)$ & $27.40(\mathrm{SD}=12.30)$ \\
\hline $\begin{array}{l}\text { Problem-solv } \\
\text { ing Task }\end{array}$ & Word & $652.00(\mathrm{SD}=179.59)$ & $602.60(\mathrm{SD}=163.78)$ \\
\cline { 2 - 4 } & AS-unit & $62.60(\mathrm{SD}=18.05)$ & $58.70(\mathrm{SD}=20.58)$ \\
\hline
\end{tabular}

Relating time on task and the use of formulaic sequences, it was found that the use of formulaic sequences and the total time on task were quite highly correlated with $\mathrm{r}=-.49(\mathrm{p}<0.05)$. This means the more formulaic sequences a speaker use, the less time he or she spends to complete the task. From this result, even though it is possible that the use of formulaic language has reduced the time needed to complete a task, we cannot be certain whether this was really the case because the correlation figure does not imply a causal relationship between the two variables. Therefore, from the high negative correlation, there can be three possible interpretations.

\subsubsection{The First: The Use of Formulaic Sequences Reduces Time on Task}

From a discourse point of view, formulaic sequences enhance comprehension by the listeners because the sequences should be popular and familiar among people in the speech community Wray, 2004 \& Hickey, 1993 [22], [23]. As messages can be understood easily, the speaker can finish their talking early. In other words, formulaic language is one of the keys to effective communication.

Another possible explanation is related to the power of formulaic sequences to maintain the focus of the discussion. This is shown in the repetitions of certain formulaic sequences by two interlocutors in a conversation. For example, the formulaic sequence deal with it was used 4 times by Shafira and 1 time by Imam in their short discussion. The repetition of deal with it showed that their discussion revolved around the same topic, that is, how to solve the problem. This suggests that neither of them was beating around the bush when they did the discussion.

The third possible explanation for why and how formulaic sequences reduce time on task is the fact that formulaic sequences are stored as a whole in the brain Wray, 2000 [24]. So the words in a sequence do not need to be decoded one after one. From a psycholinguistic point of view, comprehension of a sequence will then be faster.

\subsubsection{A Second Factor Reduces Time on Task and Enhance Use of Formulaic Sequences}

The second possible interpretation posits that both variables time on task and use of formulaic sequences are the result of a third factor. Therefore, test of correlation will show that the two variables are related to each other. This third factor, for example, can be the speaker's desire to talk (see Figure 1). If a speaker is not interested in talking, he or she may use more formulaic sequences to give general, unspecific responses like I don't know or I agree with you. As the speaker does not have the desire to talk, he or she will end the talking early. While desire to talk can be a second factor, other possibilities cannot be ruled out. Studies need to be done and post-task interviews provide useful data in the investigation.

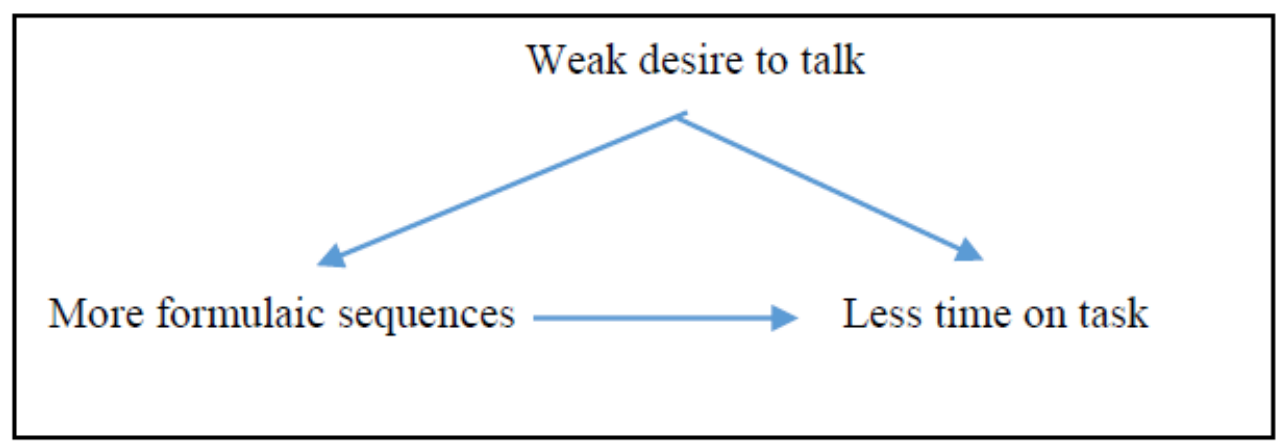

Fig.1. A Possible Relationship Between the Use of Formulaic Sequences and Time on Task

\subsubsection{A Third Factor: Limited Time Causes the Participants to Use More Formulaic Sequences $\backslash$}

There is another prediction that speakers will produce more formulaic sequences than when time pressure is absent. However, this prediction does not apply to this study because as there was no time limit for both tasks and participants could talk for as long as they wanted. Comparing these three interpretations for the high correlation $(\mathrm{r}=-.49, \mathrm{p}<.05)$ between the use of formulaic language and time on task, only the first two make 
sense in the context of this study. However, which one between the two interpretations is right requires further research.

As mentioned before, the picture task was regarded as more difficult because it was monologic and the speaker needed to rely on pausing and formulaic sequences to buy time for online planning. Therefore, speakers with greater use of formulaic sequences could thus have more online time to construct longer discourse/turns and describe in greater details of pictures than whose who did not use formulaic sequences extensively.

The problem-solving task was dialogic and it involved a lot of interaction between the two interlocutors. The pace of these interactions was so fast and immediate that once the message was understood by the listener, the listener would start to respond and the speaker did not even need to finish the whole sentence. The nature of formulaic sequences is that it is highly predictable in the sense that when the interlocutor hears I see what you mean but, the interlocutor can already be sure that opposite opinions are following. So before the speaker finishes explaining the opposite opinions, he or she may already be interrupted. Besides, while some formulaic sequences are sentence frames like I see what you mean but, a lot of formulaic sequences are full utterances that adequate in meaning. These include I agree with you, That's right, I don't know, You're a genius. These sequences are common, standard responses in our daily communication which require no explanations of the meaning. So the use of these sequences have shortened the length of each turn.

\section{Conclusions}

Pauses and formulaic sequences are devices that can be used as strategies to buy time for online planning in speaking. As the picture task, requires the speakers to speak continuously in a mono logic way, there is a greater need for the speakers to use these time-buyer devices. Lecturers in this study were better at using these devices than students.

To sum up the main findings reported in this study, lecturers in this study used more identified formulaic sequences than students but this difference was only significant in the picture task but not in the problem-solving task. However, among the lecturers and students, three styles of formulaic sequences use could be identified. The first pattern was that subjects used more formulaic sequences in the picture task than in the problem-solving task. The second pattern was vice versa; and the third pattern was subjects have similar use of identified formulaic sequences in both tasks. As these three groups balanced each other, t-test between all subjects' use of formulaic sequences in the two tasks was not statistically significant.

Fluency, measured by speech rate (both including and excluding pauses in calculation), number of pauses and mean duration of each pause, was not found to correlate with the use of formulaic sequences in general. The only high and significant correlation was between the use of formulaic sequences and mean duration of each pause for the lecturers data. As the correlation value was negative, it means the more formulaic sequences used, the shorter the duration of each pause.

Findings of this study may suggest that, first, lecturers may not always outperform students in the use of formulaic expressions as researchers assumed. In fact, as this study showed, lecturers and students may not statistically differ in their use of the identified formulaic expressions in the problem-solving task. Therefore, task type is very likely one of the factors that influence the speakers' use of formulaic expressions although this influence of task type turns out to be different depending on individuals.

The discourse function of formulaic expressions, however, differ in the sense that they seem to help speakers construct longer discourse in the picture task but shorter discourse in the problem-solving task. Finally, it is found that formulaic expressions are uttered obviously and consistently faster than the rest of utterances no matter for lecturers or students. That means changes in the rate of articulation can be an indicator of formulaic expressions and there is the possibility that this can be developed further into a method of identification for formulaic expressions. When this methodology is successfully tested in large corpora, it will provide an important solution to the difficult methodological problems that researchers face. Then it will be a breakthrough in formulaic language research.

\section{References}

[1] M. Celce-Murcia, "Rethinking the Role of Communicative Competence in Language Teaching," in Intercultural Language Use and Language Learning, M. P. S. J. Eva Alcon Soler, Ed. Dordrecht: Springer, 2007, pp. 41-58.

[2] I. Kecskes, "Formulaic language in English Lingua Franca," Language (Baltim)., no. 1, pp. 1-28, 2006.

[3] D. Wood, "Formulaic language in speech fluency development in English as a second language.," 2005. 
[4] D. Wood, "In Search of Fluency: What Is It and How Can We Teach It?," UTP Journals, vol. 4, pp. 573-589, 2001.

[5] S. D. Epstein, S. Flynn, and G. Martohardjono, "Second language acquisition : Theoretical and experimental issues in contemporary research," Behav. Brain Sci., vol. 19, pp. 677-758, 1996.

[6] V. Van Tuan, "Communicative Competence of the Fourth Year Students: Basis for Proposed English Language Program," Can. Cent. Sci. Educ., vol. 10, no. 7, p. 19, 2017.

[7] D. Newby, "Competence and performance in learning and teaching: theories and practices," in Selected Papers from the 19th ISTAL, 2011, p. 18.

[8] J. Sinclair, "Trust the text: Language, corpus and discourse," Trust Text Lang. Corpus Discourse, pp. 1-212, 2004.

[9] H. I. R. Mustapa, Yaholil \& Agustien, "Formulaic Expressions Used in Conversational Texts of the Tenth Grade's English Textbooks," English Educ. J., vol. 7, p. 15, 2017.

[10] A. Sugiati and D. Rukmini, "The Application of Formulaic Expressions in The Conversation Texts of Senior," English Educ. J., vol. 7, no. 2, pp. 103-111, 2017.

[11] N. C. Ellis, R. Simpson-Vlach, U. Römer, M. Brook O’Donnell, and S. Wulff, "Learner corpora and formulaic language in second language acquisition research," Cambridge Handb. Learn. Corpus Res., pp. 357-378, 2015.

[12] H. Neno and H. I. R. Agustien, "The Use Of Formulaic Expressions In EFL Students ' Interactions," English Educ. J., vol. 6, no. 1, pp. 39-44, 2016.

[13] D. Khusnita, Dafi \& Rukmini, "The EFL Learners ' Perceptions and Realizations of Formulaic Sequences in Casual Conversation," English Educ. J., vol. 6, no. 2, pp. 68-78, 2016.

[14] M. Rafieerad, “Analyzing Patterns of Classroom Interaction in EFL Classrooms in Iran,” vol. 7, no. 3, pp. 93-120, 2010 .

[15] N. Aini, A. Faridi, S. W. Fitriari, M. A. Nu, and H. Asy, "The Comparison of Lexical Bundles in Conversation Texts between Four Corners a nd English Intensive Course Books," vol. 8, no. 35, pp. 445-451, 2018.

[16] M. Paquot and S. Granger, "Formulaic Language in Learner Corpora," Annu. Rev. Appl. Linguist., vol. 32, pp. 130-149, 2012.

[17] H. Fogel and L. C. Ehri, "Teaching African American english forms to standard American english-speaking teachers: Effects on acquisition, attitudes, and responses to student use," J. Teach. Educ., vol. 57, no. 5, pp. 464480, 2006

[18] S. Granger, "Prefabricated patterns in advanced EFL writing: collocations and formulae .," Phraseol. Theory, Anal. Appl., no. January 1998, 2014.

[19] A. Pawley, "Formulaic speech," Int. Encycl. Linguist., no. 1960, pp. 597-602, 1992.

[20] A. Wray, "Formulaic language in learners and native speakers," Lang. Teach., vol. 32, no. 4, pp. 213-231, 1999.

[21] A. Wray, "Formulaic language in learners and native speakers," Language Teaching, vol. 32, no. 4. pp. 213-231, 1999.

[22] A. Wray, S. Cox, M. Lincoln, and J. Tryggvason, "A formulaic approach to translation at the post office: Reading the signs," Lang. Commun., vol. 24, no. 1, pp. 59-75, 2004.

[23] T. Hickey, "Title Identifying formulas in first language acquisition Author ( s ) Hickey, Tina Publication Date Publication information Publisher This item $\mathfrak{a}^{\mathrm{TM}} \mathrm{s}$ record / more information DOI Cambridge University Press," J. Child. Lang., vol. 20, pp. 27-41, 1993.

[24] A. Wray and M. R. Perkins, "The functions of formulaic language: an integrated model," Lang. Commun., vol. 20, no. 1 , pp. 1-28, 2000. 